\title{
Biochemical control after adjuvant radiation therapy for prostate cancer: a unicentric, retrospective analysis
}

\author{
Alexandru-Teodor Zaharie' ${ }^{1}$ (D) Matthias Moll ${ }^{*}$ Gregor Goldner ${ }^{1}$ \\ Received: 12 May 2020 / Accepted: 31 December 2020 / Published online: 27 January 2021
}

(c) The Author(s) 2021

\begin{abstract}
Purpose To retrospectively evaluate the biochemical no evidence of disease (bNED) and late side effects after adjuvant radiotherapy in prostate cancer patients.

Methods Patients $(n=85)$ treated with external beam radiotherapy between 1997 and 2013 following radical prostatectomy (RPE) with pathological tumour stage pT2c with positive surgical margins or pT3 and pT4 tumours with or without positive margins who presented with a postoperative and a preradiation prostate-specific antigen (PSA) level below $0.1 \mathrm{ng} / \mathrm{ml}$. The mean dose applied was $66 \mathrm{~Gy}$ with conventional fractionation (4 field box-technique). No androgen deprivation therapy was administered, and patients with incomplete data (missing Gleason score, pT stage, or PSA values postoperatively and/or prior to radiation at the presentation at our department) have been excluded from the analysis. Biochemical recurrence was defined as reaching a PSA level $>0.2 \mathrm{ng} / \mathrm{ml}$ during follow-up and bNED rates were assessed. In addition, patients were divided into two groups according to the Roach formula for predicting the risk of pelvic node involvement at a cut-off value of $15 \%$. Late urogenital and gastrointestinal side effects (EORTC/RTOG) were assessed.

Results After a median follow-up of 60 months the bNED rate was $88 \%$ at 5 years and $72 \%$ at 10 years for all patients. Patients with low risk of lymph node involvement (group $<15 \%$ ) had a 5 year and 10 year bNED of $97 \%$ and $85 \%$, while patients with high risk of positive lymph node involvement (group $>15 \%$ ) showed corresponding bNED rates of $77 \%$ and $52 \%$, respectively. A significant difference according to the Roach stratification was detected $(p \leq 0.002)$. Late urogenital (UG) and gastrointestinal (GI) grade $\geq 2$ side effects were detected in $10 \%$ and $15 \%$, respectively.

Conclusion Postoperative radiotherapy with an average dose of $66 \mathrm{~Gy}$ to the prostatic fossa following RPE provides excellent tumour control rates with acceptable side effects. Patients with a higher risk of positive lymph nodes $(>15 \%)$ according to the Roach formula show significant worse tumour control rates.
\end{abstract}

Keywords Prostate cancer $\cdot$ Radical prostatectomy $\cdot$ Adjuvant radiotherapy $\cdot$ Roach formula $\cdot$ Biochemical control

\section{Introduction}

Radical prostatectomy and primary radiotherapy are both efficient treatment options for primary localized prostate cancer with a high potential of curation. Nevertheless about $30 \%$ of patients develop biochemical recurrence after radical prostatectomy (RPE) [1, 2]. Adjuvant radiation (ART) to the prostatic fossa following radical prostatectomy has shown to provide improved local control and biochemical control for patients with pT3 tumours and or positive

Alexandru-Teodor Zaharie

alexandru.zaharie@meduniwien.ac.at

1 Department of Radiation Oncology, Medical University of Vienna, Vienna, Austria surgical margins. This has been proven by four randomised controlled trials [3-9]. However, the bNED (biochemical no evidence of disease) rates within the three randomised trials applying a dose of $60-64$ Gy were in range of $70-74 \%$ after 5 years. A recently published Finnish trial applied a dose of $66 \mathrm{~Gy}$ and reported a bNED rate of $90 \%$ after 5 years [6].

The aim of this study was to retrospectively analyse biochemical control after adjuvant radiotherapy applying a comparable high dose as used in the Finnish trial and to confirm these results. In addition a risk stratification using the Roach formula [10] was performed following a previous paper published including more patients with longer follow-up [11]. 


\section{Materials and methods}

Patients who received adjuvant radiotherapy for localised prostate cancer after radical prostatectomy with no signs of positive lymph nodes or metastasis between 1997 and 2013 in our department were analysed. This includes tumours with pathological tumour stage pT2c with positive surgical margins or pT3 and pT4 tumours with or without positive margins. All of the patients had to have a postoperative and a preradiation prostate-specific antigen (PSA) level below $0.1 \mathrm{ng} / \mathrm{ml}$. No patient received androgen deprivation therapy. Patients have received local radiotherapy limited to the prostatic fossa using a 3D-conformal technique (4-field box). The applied mean total dose was $66 \mathrm{~Gy}$, at $2 \mathrm{~Gy}$ single dose, 5 times per week. Dose range was $60-72 \mathrm{~Gy}$, where only 1 patient received a dose of $60 \mathrm{~Gy}, 2$ patients received $72 \mathrm{~Gy}$, and 5 patients $70 \mathrm{~Gy}$. The prostatic region was defined as a volume that includes the surgical limits from the seminal vesicles to the apex, with a security margin to encompass subclinical disease in the periprostatic region [7]. Target volumes were delineated according to the RTOG Consensus from 2010 [10]. A margin of $12 \mathrm{~mm}$ in all direc- tions around the clinical target volume (CTV) was added to create the planning target volume (PTV). PSA values, patient history and registration of genitourinary (GU) and gastrointestinal (GI) side-effects using the RTOG/EORTC criteria were assessed every 3 to 6 months in the first 2 years, and once a year thereafter within follow-up. Biochemical recurrence was defined as a PSA level $>0.2 \mathrm{ng} / \mathrm{ml}$ during follow-up or the introduction of hormonal treatment after radiation. In addition, patients were stratified by the Roach formula [10]:

$$
\mathrm{LN} \%=[(\text { Gleason Score }-6) \cdot 10]+2 / 3 \text { PSA }
$$

for further analysis. One group was defined by patients with a risk stratification for pelvic node involvement $<15 \%$ using the Roach formula, whereas the other group is defined as patients with a risk for pelvic node involvement $>15 \%$. All measures of time were calculated from the last day of radiotherapy. The calculation of bNED was performed using the Kaplan-Meier product limit. A $p$-value $<0.05$ was considered statistically significant. All of the statistical tests were run in SPSS 26.0. The study was approved by the local ethics committee according to local law regulations (EK Nr. 1698/2019).

Table 1 Patients' characteristics

\begin{tabular}{|c|c|c|c|c|}
\hline & Group $<15 \%$ & Group $>15 \%$ & All patients & ARO 96-02 [3] \\
\hline Number of patients & 45 & 40 & 85 & 148 \\
\hline Age at radiotherapy-mean & 63 & 65 & 64 & 65 \\
\hline iPSA-mean & $8.88 \mathrm{ng} / \mathrm{ml}$ & $9.02 \mathrm{ng} / \mathrm{ml}$ & $8.94 \mathrm{ng} / \mathrm{ml}$ & $9.7 \mathrm{ng} / \mathrm{ml}$ \\
\hline$<10 \mathrm{ng} / \mathrm{ml}$ & $38(84 \%)$ & $13(32 \%)$ & $51(60 \%)$ & n.a. \\
\hline $10-20 \mathrm{ng} / \mathrm{ml}$ & $7(16 \%)$ & $20(50 \%)$ & $27(32 \%)$ & n.a. \\
\hline$>20 n g / m l$ & - & $7(18 \%)$ & $7(8 \%)$ & n.a. \\
\hline \multicolumn{5}{|l|}{ Gleason score } \\
\hline$\leq 6$ & $28(62 \%)$ & $2(5 \%)$ & $30(35 \%)$ & $38 \%$ \\
\hline 7 & $17(38 \%)$ & $26(65 \%)$ & $43(51 \%)$ & $50 \%$ \\
\hline $8-10$ & - & $12(30 \%)$ & $12(14 \%)$ & $12 \%$ \\
\hline \multicolumn{5}{|l|}{ Pathological tumour stage } \\
\hline$p T 2 c$ & $21(47 \%)$ & $11(27.5 \%)$ & $32(38 \%)$ & $3 \%$ \\
\hline$p T 3$ & $19(42 \%)$ & $26(65 \%)$ & $45(53 \%)$ & $94 \%$ \\
\hline$p T 4$ & $5(11 \%)$ & $3(7.5 \%)$ & $8(9 \%)$ & $3 \%$ \\
\hline Positive resection margins & $42(93 \%)$ & $39(97.5 \%)$ & $81(95 \%)$ & $68 \%$ \\
\hline Lymphadenectomy performed & $13(29 \%)$ & $17(42.5 \%)$ & $30(35 \%)$ & $100 \%$ \\
\hline $\begin{array}{l}\text { Numbers of LN removed-mean } \\
\text { (min-max) }\end{array}$ & $\begin{array}{l}5 \\
(2-10)\end{array}$ & $\begin{array}{l}9 \\
(2-44)\end{array}$ & $\begin{array}{l}7 \\
(2-44)\end{array}$ & n.a. \\
\hline $\begin{array}{l}\text { PSA postoperative ng/ml-mean } \\
\text { (min-max) }\end{array}$ & $\begin{array}{l}0.02 \\
(0-0.1)\end{array}$ & $\begin{array}{l}0.02 \\
(0-0.1)\end{array}$ & $\begin{array}{l}0.02 \\
(0-0.1)\end{array}$ & $\begin{array}{l}<0.1 \\
100 \%\end{array}$ \\
\hline $\begin{array}{l}\text { PSA prior RT ng/ml-mean } \\
\text { (min-max) }\end{array}$ & $\begin{array}{l}0.02 \\
(0-0.1)\end{array}$ & $\begin{array}{l}0.03 \\
(0-0.1)\end{array}$ & $\begin{array}{l}0.02 \\
(0-0.1)\end{array}$ & $\begin{array}{l}<0.1100 \% \\
<0.0580 \%\end{array}$ \\
\hline Time RPE to RT in months-median & 3 & 4 & 4 & 3.5 \\
\hline $\begin{array}{l}\text { Local Radiation dose Gy-mean } \\
\text { (min-max) }\end{array}$ & $\begin{array}{l}66.4 \mathrm{~Gy} \\
(60-72 \mathrm{~Gy})\end{array}$ & $\begin{array}{l}66.2 \mathrm{~Gy} \\
(66-72 \mathrm{~Gy})\end{array}$ & $\begin{array}{l}66.3 \mathrm{~Gy} \\
(60-72 \mathrm{~Gy})\end{array}$ & $60 \mathrm{~Gy}$ \\
\hline $\begin{array}{l}\text { Follow-up in months-median } \\
\text { (min-max) }\end{array}$ & $\begin{array}{l}72 \\
(12-174)\end{array}$ & $\begin{array}{l}54 \\
(1-197)\end{array}$ & $\begin{array}{l}60 \\
(1-197)\end{array}$ & 54 \\
\hline 5 year bNED rate & $97 \%$ & $77 \%$ & $88 \%$ & $72 \%$ \\
\hline
\end{tabular}

$i P S A$ initial prostate specific antigen, $L N$ lymph nodes, $R T$ radiotherapy, $R P E$ radical prostatectomy 


\section{Results}

Between 1997 and 2013, a total of 1453 patients received postoperative radiotherapy for prostate cancer at our department. Out of this population, 188 patients were nodal positive or had metastasis $(\mathrm{N}+$ or $\mathrm{M}+)$ and 390 patients did not have a documented Gleason sore, pT stage, or PSA value (either preoperative, postoperative or prior to radiation); these were also excluded. From the remaining 875 men, 230 have received additional hormonal therapy and 499 had to be excluded due to salvage radiation. Therefore, 146 patients remained, of which 14 had additional pelvic node irradiation and 41 patients received hypofractionated radiation. From the remaining 91 patients, 6 more were excluded for having a PSA value postoperatively or prior to radiation between $0.1-0.2 \mathrm{ng} / \mathrm{ml}$, in order to comply with the current definition of ART, resulting to a cohort of 85 patients.

Most patients had a Gleason score 7 or pT3 stage. Nearly all of the patients included presented with positive surgical margins (95\%). A pelvic lymph node dissection was performed in $35 \%$ of the patients and the average number of lymph nodes removed was 7 . The details of the patient characteristics are shown in Table 1.

After a median follow-up of 60 months the bNED rate was $88 \%$ at 5 years and $72 \%$ at 10 years for all patients. A significant difference according to the Roach stratification could be detected $(p \leq 0.002)$. Patients with low risk of lymph node involvement (group $<15 \%$ ) had a 5 -year and 10-year bNED of $97 \%$ and $85 \%$, while patients with high risk of positive lymph nodes (group $>15 \%$ ) showed corresponding bNED rates of $77 \%$ and $52 \%$, respectively (Fig. 1).

When addressing side-effects, grade 2 or higher toxicity measured by the RTOG/EORTC criteria was registered in $14 \%$ of the patients regarding GU effects and $11 \%$ when
Table 2 Late urogenital (UG) and gastrointestinal (GI) side-effects (RTOG/EORTC)

\begin{tabular}{lllll}
\hline Grade & UG $(n)$ & $\%$ & GI $(n)$ & $\%$ \\
\hline 0 & 50 & 59 & 53 & 62 \\
1 & 22 & 26 & 22 & 26 \\
2 & 9 & 11 & 8 & 9 \\
3 & 3 & 4 & 1 & 1 \\
Missing & 1 & 1 & 1 & 1 \\
Total & 85 & 100 & 85 & 100 \\
\hline
\end{tabular}

regarding GI effects (Table 2). Grade 3 toxicity was reported in 4 patients: 3 genitourinary and 1 gastrointestinal toxicity. The GI event was a rectal ulcer, which was diagnosed 13 months after radiation and treated successfully conservatively. The GU events were all urethral strictures which developed at different points of time: 2 months, 22 months and 108 months follow-up. One of the patients received a urethral dilation while the other two received a transurethral resection. Postinterventional, the obstructive symptoms relieved in all patients. The urethral dilation had to be repeated after several weeks.

\section{Discussion}

The aim of our study was to evaluate bNED rates after adjuvant radiotherapy for prostate cancer in comparison to published data and to investigate whether the Roach formula can predict the risk of biochemical recurrence. Beside its retrospective nature our study shows additional limitations such as the low number of patients included, the median follow-up is rather short, and the high drop-out rate of the patients during follow-up.

The recently published Finnish randomized trial of adjuvant radiotherapy versus observation after radical prosta-
Fig. 1 Kaplan-Meier curves showing the bNED value at 5 and 10 years respectively. Group $<15 \%$ is represented by the blue line, group $>15 \%$ is shown through the red line, the black line represents all patients. $n$ number of observations at the corresponding time-points

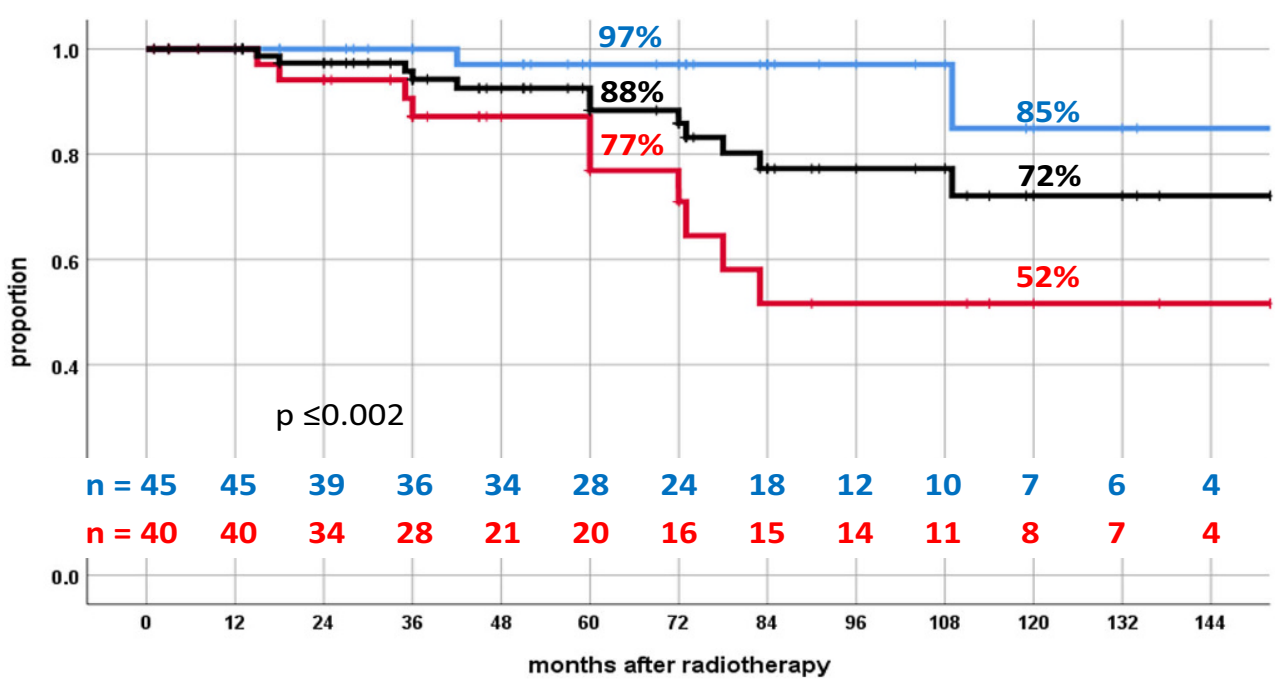


tectomy included 250 patients in total, 121 in the treatment arm [8]. Hackman et al. reported, after a median follow-up of over 9 years, a 5-year biochemical free survival rate of $90 \%$ compared to the 3 randomised clinical trials ARO-096, EORTC 22911 and SWOG 8794 [3-7] reporting about a 5-year biochemical free survival rate of $70-74 \%$. This improvement might be caused by the higher local dose of 66.6 Gy applied in contrast to 60-64 Gy. However, more dose might lead to a better bNED, but this does not necessarily translate into other clinical endpoints like better metastasis-free survival or improved cancers-specific or overall survival. Within our analysis, patients included received a mean dose of $66.3 \mathrm{~Gy}$ and we were able to detect a comparable tumour control rate of $88 \%$ after 5 years. However, the Finnish trial had several limitations. First of all more than $50 \%$ of patients included had a PSA postoperative and before radiotherapy of $0.2-0.5 \mathrm{ng} / \mathrm{ml}$, patients with seminal vesical invasion were excluded and tumour progression was defined by reaching a PSA $>0.4 \mathrm{ng} / \mathrm{ml}$. The patients included in our analysis had a mean PSA after RPE and prior to radiotherapy of $0.02 \mathrm{ng} / \mathrm{ml}$ pretty much comparable to the German ARO-96 study (Table 1). In addition we defined biochemical recurrence by reaching a PSA $>0.2 \mathrm{ng} / \mathrm{ml}$. Nearly all our patients $(95 \%)$ presented with positive surgical margin in contrast to $68 \%$ in the German trial. Nevertheless, we were able to confirm the excellent tumour control rates of the Finnish trial validating their results.

We further investigated the impact of the Roach formula on the biochemical free survival by defining two different groups. The two groups were balanced concerning number of patients, age, tumour stage, positive resection margin and postoperative and preradiotherapy PSA (Table 1). All patients received local radiotherapy limited to the prostatic fossa. Patients with low risk of positive lymph nodes according to the Roach formula $(<15 \%)$ showed a significant better tumour control rate than patients with high risk of positive lymph node after 5 years $(97 \%$ vs. $77 \% ; p=0.002)$. Only $2 / 45(4 \%)$ patients vs. $10 / 40(25 \%)$ patients presented with biochemical recurrence. To further improve the results from adjuvant radiotherapy, especially in patients with high risk of lymph node involvement, additional treatment strategies could be evaluated. The RTOG 9413 trial [12] for primary prostate cancer radiotherapy showed superior results for high-risk lymph node positive (Roach $>15 \%$ ) patients after whole pelvic lymph node radiotherapy. In accordance, one might assume that within postoperative radiotherapy — either adjuvant or salvage setting—such patients might benefit from additional pelvic lymph node irradiation. Spiotto et al. [13] demonstrated such benefit with a 5year bNED rate of $36 \%$ for patients treated at the prostatic fossa only compared to $53 \%$ for patients receiving also pelvic lymph node irradiation. Within a multi-institutional retrospective trial from 894 patients Fiorino et al. were able to demonstrate that tumour relapses after postoperative prostate cancer radiotherapy frequently result from clonogens outside the irradiated volume, supporting the choice of lymph-node irradiation, systemic therapy or both for specific subgroups such as Gleason score $\geq 7$ patients. Initial results of the RTOG 0534 SPPORT trial were reported at the 2019 ASTRO meeting. This 3 arm trial randomized 1736 patients to salvage radiotherapy to the prostate bed, salvage radiotherapy to the prostate bed and androgen deprivation therapy, or salvage radiotherapy to the prostate bed + ADT + radiotherapy to the pelvic lymph nodes. The 5 -year freedom from progression rate was $71 \%$ for salvage radiotherapy to the prostate bed, $81 \%$ for salvage radiotherapy to the prostate bed ADT, and $87 \%$ for salvage radiotherapy to the prostate bed + ADT + radiotherapy to the pelvic lymph nodes [13].

Side-effect reporting in our analysis, as well as in the ARO-96 and EORTC trials was done using the RTOG/EORTC grading system. The EORTC study [4] revealed more toxicity in the radiation arm than in the RPE only arm, with an overall grade 3 toxicity of $5.3 \%$ versus $2.5 \%$. Grade 2 or higher events occurred with an incidence of $21.3 \%$ versus $13.5 \%$ regarding the genitourinary tract, and $2.3 \%$ versus $1.9 \%$ incidence regarding the gastrointestinal tract, reported on a cohort of 512 men. The ARO-96 trial [3] reported one grade 3 genitourinary adverse event and three grade 2 events, while only two grade 2 sideeffects regarding the gastrointestinal tract. Overall grade 1 reactions were reported in $21.9 \%$ of the 114 men. Our analysis revealed an overall grade 1 toxicity in $34 \%$ of the patients, with an increased incidence of overall grade 2 adverse events in around 19\% and grade 3 adverse events in $5 \%$ of the men. This increase compared to the German trial might be due to the higher applied dose.

\section{Conclusion}

We were able to confirm the results from the Finnish trial showing improved biochemical recurrence free survival rates for patients receiving adjuvant radiotherapy after radical prostatectomy with a local dose of at least $66 \mathrm{~Gy}$ with an acceptable toxicity profile. Furthermore, patients with higher risk of positive lymph nodes ( $>15 \%)$ according to the Roach formula show significant worse tumour control rates.

Funding Open Access funding provided by Medical University of Vienna

Conflict of interest A.-T. Zaharie, M. Moll and G. Goldner declare that they have no competing interests. 
Open Access This article is licensed under a Creative Commons Attribution 4.0 International License, which permits use, sharing, adaptation, distribution and reproduction in any medium or format, as long as you give appropriate credit to the original author(s) and the source, provide a link to the Creative Commons licence, and indicate if changes were made. The images or other third party material in this article are included in the article's Creative Commons licence, unless indicated otherwise in a credit line to the material. If material is not included in the article's Creative Commons licence and your intended use is not permitted by statutory regulation or exceeds the permitted use, you will need to obtain permission directly from the copyright holder. To view a copy of this licence, visit http://creativecommons.org/licenses/by/4. $0 /$.

\section{References}

1. Joniau S et al (2015) Stratification of high-risk prostate cancer into prognostic categories: a European multi-institutional study. Eur Urol 67(1):157-164

2. Briganti A et al (2015) Natural history of surgically treated highrisk prostate cancer. Urol Oncol 33(4):163.e7-163.13

3. Wiegel $\mathrm{T}$ et al (2009) Phase III postoperative adjuvant radiotherapy after radical prostatectomy compared with radical prostatectomy alone in pT3 prostate cancer with postoperative undetectable prostate-specific antigen: ARO 96-02/AUO AP 09/95. J Clin Oncol 27(18):2924-2930

4. Bolla M et al (2005) Postoperative radiotherapy after radical prostatectomy: a randomised controlled trial ( EORTC trial 22911 ). Lancet 366:572-578

5. Thompson IM et al (2009) NIH public access author manuscript. Author manuscript; available in PMC 2012 November 30. Pub- lished in final edited form as: J Urol J Urol . 2009 March; 181(3): 956-962. doi:10.1016/j.juro.2008.11.032. Adjuvant radiotherapy for pathologic T3N0M0 prosta. J Urol 181(3):956-962

6. Spratt DE (2019) The Finnish randomized trial of adjuvant radiotherapy versus observation after prostatectomy: almost a trial of adjuvant versus late salvage radiotherapy. Eur Urol 76(5):596-598

7. Roach M et al (1994) Predicting the risk of lymph node involvement using the pre-treatment prostate specific antigen and gleason score in men with clinically localized prostate cancer. Int J Radiat Oncol Biol Phys 28(1):33-37

8. Goldner G, Dimopoulos J, Pötter R (2010) Is the Roach formula predictive for biochemical outcome in prostate cancer patients with minimal residual disease undergoing local radiotherapy after radical prostatectomy? Radiother Oncol 94(3):324-327

9. Wiegel $\mathrm{T}$ et al (2014) Adjuvant radiotherapy versus wait-and-see after radical prostatectomy: 10-year follow-up of the. Eur Urol 66:243-250

10. Michalski JM et al (2010) Development of RTOG consensus guidelines for the definition of the clinical target volume for postoperative conformal radiation therapy for prostate cancer. Int J Radiat Oncol Biol Phys 76(2):361-368

11. Thompson IMJ et al (2006) Adjuvant radiotherapy for pathologically advanced prostate cancer: a randomized clinical trial. JAMA 296(19):2329-2335

12. Stephenson AJ et al (2012) Postoperative radiation therapy for pathologically advanced prostate cancer after radical prostatectomy. Eur Urol 61(3):443-451

13. Pollack A et al (2018) Short term androgen deprivation therapy without or with pelvic lymph node treatment added to prostate bed only salvage radiotherapy: the NRG Oncology/RTOG 0534 SPPORT trial. Int J Radiat Oncol Biol Phys 102(5):1605 